\title{
METÁSTASIS CUTÁNEA DE TUMOR UROTELIAL VESICAL
}

\author{
D. PASCUAL REGUEIRO, A. GARCÍA DE JALÓN MARTÍNEZ, C. SANCHO SERRANO, \\ E. MALLÉN MATEO, M.J. GIL SANZ, J. AZÚA ROMEO*, L.A. RIOJA SANZ
}

Servicio de Urología. *Servicio de Anatomía Patológica. Hospital Universitario Miguel Servet. Zaragoza.

Actas Urol Esp. 27 (1): 43-46, 2003

\section{RESUMEN}

"METÁSTASIS CUTÁNEA DE TUMOR UROTELIAL VESICAL"

Queremos presentar un caso de carcinoma vesical de células transicionales, donde el primer signo de progresión de la enfermedad fue la aparición de una metástasis cutánea.

Una manifestación inusual en un paciente sin otras lesiones metastásicas.

PALABRAS CLAVE: Metástasis cutáneas. Carcinoma transicional vesical.

\section{ABSTRACT \\ "SKIN METASTASES OF UROTHELIAL CANCER OF THE BLADDER"}

We want to present a case of transicional cell bladder carcinoma, where the first sign of disease progression was the appearence of a skin metastase.

An unusual manifestation in a patient without another metastatic lesions.

KEY WORDS: Skin metastases. Transicional bladder carcinoma.

$\mathrm{L}$

a historia natural de los carcinomas transicio-

nales vesicales, pasa por la invasión progresiva de la pared vesical y posterior diseminación a distancia en forma de metástasis en otros órganos y tejido linfático, y progresión local con invasión de estructuras adyacentes.

Aunque los avances diagnósticos y terapéuticos permiten que la mayor parte de dichas neoplasias se diagnostiquen en fases iniciales, en algunas ocasiones el debut de la enfermedad se produce en forma de una tumoración infiltrante o con progresión local o a distancia.

Las metástasis cutáneas, aunque poco frecuentes, están descritas en multitud de tumoraciones, apareciendo casi siempre en casos avanzados en los que existe diseminación a otros niveles.

Queremos presentar un caso de carcinoma transicional vesical, que debutó en forma infil- trante y cuya primera manifestación de diseminación a distancia fue una metástasis cutánea única.

\section{CASO CLÍNICO}

Se trata de un varón de 75 años de edad, sin antecedentes patológicos de interés, salvo un hábito tabáquico dilatado a lo largo de toda su vida.

Seguido y controlado en nuestras consultas por un síndrome prostático, se realizó en diciembre de 1995 una adenomectomía transvesical, llevándose a cabo en la misma intervención una resección de un amplio divertículo vesical, en el seno de una vejiga de esfuerzo trabeculada y multidiverticular.

El último control se realizó en 1998, encontrándose el paciente muy satisfecho con su micción y con un PSA de 0,64. 
Volvemos a tener contacto con el paciente en diciembre de 2001. Relata un episodio de hematuria total y monosintomática hace un mes, seguida de episodios alternantes y caprichosos del mismo cuadro, a lo que se ha añadido en estos últimos días un dolor en flanco izquierdo.

La exploración y analítica general resultan ser normales así como la exploración radiológica simple.

Se solicita un estudio más completo, que incluye unas citologías, que resultan positivas, una ECO abdominal, con los hallazgos de un quiste cortical en el riñón derecho y una imagen no clara en cara lateral izquierda vesical.

Ante estos hallazgos se realiza una urografía intravenosa que demuestra la existencia de un divertículo vesical en cara lateral izquierda vesical, con duda de defecto de replección en su interior en las placas post-miccionales.

Dicho hallazgo se confirma con las imágenes del TAC (Fig. 1).

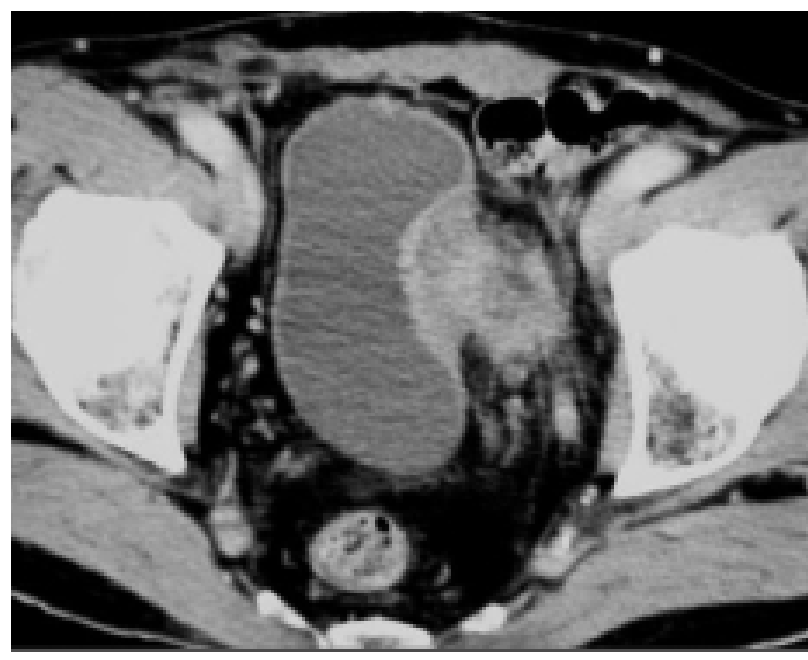

FIGURA 1. Imagen del TAC donde se aprecia el diverticulo ocupado por la tumoración, sin evidencia de progresión local.

El paciente es ingresado llevándose a cabo una revisión endoscópica en marzo de 2002 con los siguientes hallazgos:

Vejiga multidiverticular de esfuerzo.

Gran divertículo en cara lateral izquierda, ocupado en su interior por una tumoración de aspecto sólido e infiltrante.

El post-operatorio transcurre sin incidencias, obteniéndose los siguientes resultados:
A.P.: carcinoma transicional vesical T2 G3 con biopsias vesicales múltiples negativas.

Citologías selectivas ureterales por lavado negativas.

Ante estos hallazgos y el buen estado general del paciente, sin evidencias de diseminación a distancia (Rx de tórax, ECO abdominal y TAC abdominal sin signos de metástasis pulmonares, ni hepáticas, ni ganglionares, ni afectación de próstata ni ángulos vésico-seminales), se decide llevar a cabo una actuación más radical.

En este punto aclarar que nos encontramos ante un tumor urotelial $\mathrm{T} 2$, intradiverticular, lo que determina un mayor grado de invasión parietal del tumor, ya que como de todos es conocido, los divertículos vesicales son una herniación de la mucosa entre los haces musculares, careciendo de capa muscular propiamente dicha.

Teniendo en cuenta todos los factores, se decide llevar a cabo una cistectomía parcial una semana después.

En el acto quirúrgico se confirman los mismos hallazgos, resecándose toda la pared vesical que albergaba el divertículo con la tumoración en su interior, realizándose en el mismo acto una reimplantación del uréter izquierdo.

La evolución post-operatoria urológica es correcta, con diuresis adecuadas e inactividad del drenaje.

Sin embargo en el noveno día del post-operatorio, comienza con un cuadro febril, empeoramiento progresivo del estado general y distensión abdominal importante.

Se realiza TAC de urgencia hallándose una colección paravesical de aspecto abscesificado con intensa dilatación de asas de delgado y derrame pleural bilateral.

El empeoramiento del paciente es muy importante, con aparición de disnea importante e insuficiencia cardíaca, por lo que se decide su traslado a la Unidad de Cuidados Intensivos.

Conjuntamente con el Servicio de Cirugía General, se realiza laparotomía exploradora, con drenaje del absceso paravesical y reparación de una pequeña perforación de intestino delgado producida durante las maniobras de disección.

La evolución inicial del enfermo es favorable con desaparición de la fiebre y del íleo intestinal. 
Sin embargo una semana después de la cirugía, el cuadro comienza a empeorar con aparición de contenido de aspecto intestinal a través de la laparotomía, reaparición de la fiebre, e imposibilidad de desintubar al enfermo, al cual se realiza traqueostomía para mantener el respirador.

Durante su estancia en la UCI se evidencia la aparición de una lesión nodular en la zona pectoral derecha, no adherida, redondeada que dobla su tamaño en cuestión de una semana (Fig. 2).

Se realiza punción aspiración con aguja fina (PAAF) de dicha tumoración pectoral obteniéndose un material líquido, de coloración rosada. La PAAF se lleva a cabo con aguja de $23 \mathrm{G}$ y dispositivo Cameco ${ }^{\circledR}$, practicando un total de 3 punciones. Se fijan en alcohol $2 / 3$ de los portaobjetos, mientras que el resto fijan al aire. Posteriormente se tiñen con la técnica de Papanicolaou los primeros y con el método de Giemsa los secados al aire.

Al microscopio óptico se objetiva una celularidad muy abundante, habitualmente en forma de células sueltas, aunque también se observan agregados pseudopapilares. La célula presenta una talla grande con desproporción núcleo/citoplasma, irregularidad nuclear, nucleolos patentes y múltiples, cromatina tosca y prolongaciones citoplasmáticas. Las mitosis no son frecuentes.

Con estos hallazgos se puede afirmar que se trata de una metástasis cutánea de una neoplasia epitelial, muy probablemente de tracto génito-urinario.

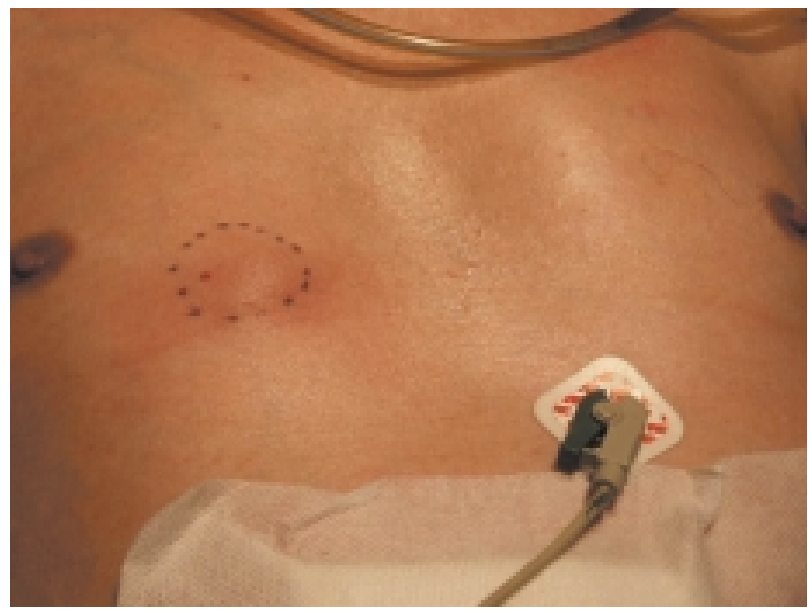

FIGURA 2. Imagen macroscópica donde se puede apreciar rodeada por una linea de puntos, lesión nodular subcutánea, en zona pectoral derecha.
Con el antecedente de neoplasia de vejiga se realizan técnicas de inmunohistoquímica para los marcadores epiteliales (queratina $\mathrm{AE} 1 / \mathrm{AE} 3$ ), próstata (PSA) y melanoma (HMB-45 y S-100), resultando positivo únicamente para las queratinas, lo que ratifica el diagnóstico inicial (Fig. 3).

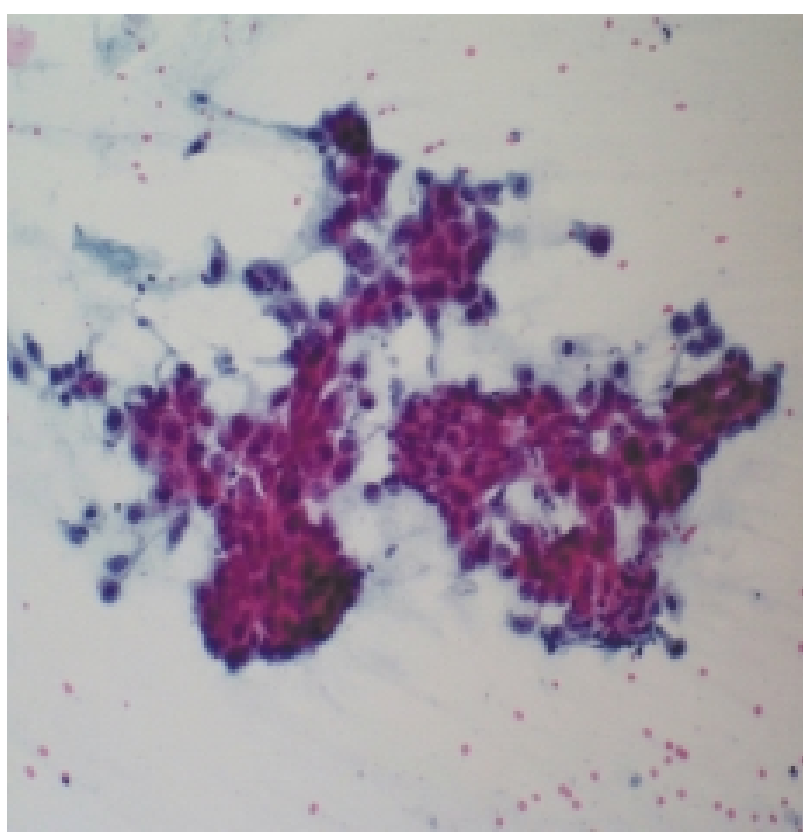

FIGURA 3. Tinción de papanicolaou x 15 aumentos celularidad muy abundante, habitualmente en forma de células sueltas, aunque también se observan agregados pseudopapilares.

La evolución del paciente es desfavorable, encontrándose, en el momento de redactar este artículo en situación precaria, con ventilación asistida y sin posibilidad de actuación, siendo el pronóstico infausto.

\section{COMENTARIO}

Como vemos, se trata de un caso de tumor urotelial vesical, cuya primera manifestación ha sido en forma de neoplasia infiltrante, lo que ha sido favorecido por su localización intradiverticular.

No obstante, el carácter localizado de la lesión, sin signos de progresión local ni metastásica a distancia, nos animó a llevar a cabo una opción de tratamiento con una intención en principio curativa.

La evolución post-operatoria fue nefasta, aunque cabe decir que la cirugía resultó compleja, con resección de una importante cantidad de pared 
vesical, que obligó a la reimplantación ureteral izquierda, y que terminó con la formación de una colección abscesificada paravesical, lo que se siguió de un cúmulo de complicaciones originando todo ello el fatal desenlace.

Lo llamativo del caso y por lo que creemos oportuno su difusión, es la aparición de una metástasis cutánea como primer y único signo de diseminación a distancia de la enfermedad, cuando de todos es sabido que los lugares donde más frecuentemente metastatizan los carcinomas transicionales son los ganglios linfáticos, hígado, pulmón y hueso, siendo las lesiones cutáneas más propias de enfermedades de largo tiempo de evolución y ampliamente diseminadas.

\section{REFERENCIAS}

1. NOUIRA Y, KBAIER I, ATTYAOUI F, HORCHANI A: Skin metastases of urothelial carcinoma of the bladder: a case report. Tunis Med 1999 apr; 77 (4): 233235.

2. BEAUTYMAN EJ, GARCIA CJ, SIBULKIN D, SNYDER PB: Transitional cell bladder carcinoma metastatic to the skin. Arch Dermatol 1983 aug; 119 (8): 705-707.

3. WYLDES MP, OSBORN DE: Solitary cutaneous metastasis from transitional cell carcinoma of the bladder. Br J Urol 1988 feb; 61 (2): 164.

4. REBELAKOS A, MANTHOPOULOS A, HADJISSOTIRIOU GG: Unusual metastasis of bladder cancer. $\mathrm{Br}$ J Urol 1989 aug; 64 (2): 198.
5. FUJITA K, SAKAMOTO Y, FUJIME M, KITAGAWA R: Two cases of inflammatory skin metastasis from transitional cell carcinoma of the urinary bladder. Urol Int 1994; 53 (2): 114-116.

6. SEREL TA, OZDEMIR G, YAMAN LS, OZDEMIR H: Skin metastasis of bladder carcinoma. A case report. Mater Med Pol 1994 jul-sep; 26 (3): 113-114.

7. SPECTOR JI, ZIMBLER H, DELEO M, ROSS JS: Skin metastases from transitional cell bladder cancer. Urology 1987 feb; 29 (2): 215-217.

8. SAFER LF, PIROZZI DJ: Extensive cutaneous metastases from urinary bladder carcinoma. Cutis 1980 nov; 26 (5): 485-486, 500.

9. JARA J, HERNÁNDEZ C, RODRÍGUEZ-COSTA J, MONCADA I, BASQUERO B, ESCRIBANO G, PARDO $\mathrm{E}$ : Skin metastasis as the first manifestation of dissemination of bladder cancer. Actas Urol Esp 1989 nov-dec; 13 (6): 480-481.

10. GALLEGO SÁNCHEZ JA, GAMARRA QUINTANILLA M, IBARLUCEA G, LARRINAGA SIMÓN J: Skin metastasis from transitional cell carcinoma of the bladder. Arch Esp Urol 1999 dec; 52 (10): 1.092-1.094.

11. SAITO S: Solitary cutaneous metastasis of superficial bladder cancer. Urol Int 1998; 61 (2): 126-127.

12. TAKIGAWA H, KAGAWA S, AGA Y, FURUKAWA A, INAI T, KUROKAWA K: Cutaneous metastases from transitional cell carcinoma of the bladder. Hinyokika Kiyo 1989 jun; 35 (6): 1.061-1.063.

Dr. D. Pascual Regueiro

Avda. Compromiso de Caspe, 27-29, 2ํㅗ

50002 Zaragoza

(Trabajo recibido el 4 mayo de 2002) 